\title{
The Role of Ethnomedicinal Plants for Treatment and Management of Diabetes Mellitus: An Updated Review
}

\author{
Rakesh K Sindhu $^{1 *}$, Balraj Saini ${ }^{1}$, Prabhjot Kaur ${ }^{1}$, Sandeep Arora ${ }^{1}$, Gaber El-Saber Batiha ${ }^{2}$ \\ ${ }^{1}$ Chitkara College of Pharmacy, Chitkara University, Punjab, India \\ ${ }^{2}$ Department of Pharmacology and Therapeutics, Faculty of Veterinary Medicine, Damanhour \\ University, Damanhour Egypt \\ Email: rakesh.sindhu@ chitkara.edu.in
}

DOI: $10.51201 /$ JUSST/21/07213

http://doi.org/10.51201/JUSST/21/07213

\begin{abstract}
Diabetes mellitus is one of the prominent metabolic disorders nowadays worldwide and it is characterized by an increase in blood glucose, disturbances in the metabolism, and alteration in insulin secretion. Nowadays, phytopharmaceuticals has become a significant treatment mode for the diabetes, and bioactive compounds have expanded an increasing amount of consideration to this end for they have multiple biological potential, including the sustained secretion of insulin and revival of pancreatic islets cells. In this review article, we explained the role of bioactive compounds in treatment and management diabetes, and their mechanisms in the prevention.
\end{abstract}

Keywords: Diabetes mellitus, bioactive compounds, insulin, blood glucose.

\section{INTRODUCTION:}

One of the oldest and fastest growing chronic metabolic disorders is Diabetes. A disorder which is identified by raised levels of glucose commonly known as hyperglycemia which may due to inadequacy in secretion of insulin which may further lead to chronic hyperglycemia [1-2]. Insulin is required as an energy source for consumption or utilization of glucose and is generally synthesized as a hormone in the pancreatic beta cells. This inadequacy results in various abnormalities leading to complications in macro and micro level with increased cardiovascular disorders [3]. 
Diabetes has been now seen a global epidemic disorder due to more advancement in industrialization and increasing obesity in individuals. According to recent surveys it is predicted that diabetes will be increased from 4\% in 1995 to $6.4 \%$ in 2025[4]. By the year 2025 the most affected countries are predicted to be China, USA and India. No. of individuals suffering will be increased from 194 million to 380 million [5].

Due to change in lifestyle and increased exposure to various chemical products as well as changing eating habits have increased the no. of individuals suffering from diabetes, affecting mainly the urban areas. Diabetes additionally produce short and long term affects which affect largely the individuals leading to increase in premature death rates [6]. Consequences of diabetes may lead to ulceration[7,8], neuropathy[9,10], CVS complications [11,12] and retinopathy [13,14], nephropathy $[15,16]$. Historically, Diabetes was about reported 3000 years ago in the manuscript of Egypt [17]. Diabetes has been classified into Type- I and Type- II. A clear Distinction b/w Type -I Diabetes and Type- II were made in the year 1936[18]. Based on the clinical and etiology Diabetes may largely classified into four classes

1. Type I Diabetes

2. Type 2 Diabetes

3. Gestational Diabetes

4. Other Specific class

Type-I is considered as Major class in most of the individuals, thought it also affect the younger age which should be considered worryful. The impact of this has been on rich as well as poor countries of the world [19]. Diabetes have now become the most serious topic globally and various measures are taken to treat this. This has been found that it may be caused due to various factors such as changed lifestyles, behavior patterns, urbanization and dietary changes and many more [20]. In almost every part of the population there is case of diabetes found as well as glucose intolerance [21]. Diabetes may further cause cerebrovascular diseases, cardiovascular as well as peripheral diseases. The next type of diabetes -Type -II diabetes cause irregular secretion of insulin and insulin peripheral resistance ${ }^{[22]}$. Historically in the $6^{\text {th }}$ century BC diabetes was classified as Medhumeha by Sushruta. He also described the treatment by exercise and good lifestyle [23]. Characteristic loss of weight, excessive passage of urine (polyuria), and vision impairment is some of the 
symptoms of Diabetes. Chronic conditions may lead to ketoacidosis further leading to stupor and death, if not treated [24]. Various drugs are available for the treatment, the main aim to treat the disease or prevent long term complication by reducing the risk factors [25].

\section{DIABETES CLASSIFICATION}

According to revised classification of diabetes, clinical as well as etiological categories are covered. Etiological category includes better understanding of cause of diabetes. Clinical category involves various clinical stages of diabetes in its history. They are categorized on the basis of the stage of developing diabetes, as by the clinical characteristics [26]. Following are the types of diabetes:

1. Type-I diabetes mellitus:

In this type diabetes there is absence of insulin due to ruination of pancreatic Beta cells. Individuals genetically adequately form autoimmune response that destroy beta cells are more affected. There exist two types of diabetes type -I. Firstly autoimmune markers such as antibodies such as insulin and auto antibodies, islet cell antibodies causing immune -mediated disease. Mainly 85-90 percent are affected by this type. Secondly, Idiopathic type -I diabetes; whose cause is not known. Only few people people are affected by this [27]. Thirstiness, excessive urination, hyperglycemia, ketoacidosis are the various symptoms of this category [28].

2. Type-II diabetes mellitus:

One of the most common type of diabetes and is increasing. Due to low level of insulin secretion, leading to unwieldy absorption of glucose for energy into the cell. There are $90 \%$ of registered cases of diabetes affecting population above age of 65 [29]. They more reported in adults as compared to children. This form is mainly characterized by skin darkening and insulin resistance [30]. Normally patients suffering remain unrecognized and are asymptomatic. Insulin resistance is developed characterized by upper body obesity. Therefore, insulin secretion is increased for the compensation by Beta cells. Insulin dependency is caused due to loss of Beta cell [27].

3. Gestational diabetes: 
Due to rapid hormonal changes during pregnancy there develops gestational diabetes. It mainly results due to body change for the consumption of insulin which leads to intolerance of carbohydrates. Though this type disappears after the child birth and infant born may or may not have diabetes [31]. The patient may develop IGT, type 2 diabetes or type 1 in the later life. Proper assessments should be done along with glucose testing marking the characteristics of risks during pregnancy [32].

4. Maturity Onset Diabetes

MODY (Maturity onset of diabetes of young), a type of monogenic diabetes includes minority of patients. It leads to mutation of genes such as glucokinase gene (MODY-2), HNF - I alpha, NEUROD 1 etc.HNF-1 alpha gene is the commonest [33].

\section{ETIOLOGY}

\section{Etiology of Diabetes - Type-I}

Due to destruction of pancreatic Beta- cells there is reduced formation of insulin. Usually the symptoms are seen only for a short time or not at time. Also, genes such as human leukocyte antigens commonly called HLAS on WBC's Cause the risk of Type -I diabetes [34, 35]. Other factors include:

Environmental Factors: Factors such as toxins, food and viruses may cause type 1 diabetes.

Viruses and Infections: Though virus may not be cause for diabetes as such they include viruses which may be associated like rubella, mumps which may further produce type -I diabetes.

Destruction of Cells: T- cells in the lymphatic system may destroy Beta cells and cause type-1 diabetes [36].

Etiology of Type- II

1. Hyperthyroidism 
2. Insulin gene mutations

3. Mature onset diabetes of the youth

4. Mutations in insulin receptor

5.mutations in mitochondria [37-40].

\section{OTHER ETIOLOGICAL FACTORS:}

1. Diseases related to endocrine system

2. Impairment of beta cells by drugs treating HIV

3. Syndrome such as - Klinefelter syndrome

- Turner syndrome

- Down Syndrome

- Cushing syndrome

4. Chemical toxins [27]

\section{PATHOPHYSIOLOGY: TYPE-I (IDDM)}

Type-I occurs as result of destruction of Beta cells in the pancreas which is an autoimmune disease. The principal is hormone that help in the regular uptake of glucose from the blood to various cells. Hence deficiency of insulin results in diabetes. The function of pancreatic cells functions abnormally along with the deficiency of insulin. There is marked excess of glucagon. This excessive secretion of glucagon results in various metabolic effects caused by deficiency oof insulin. IDDM individuals generally develop Ketoacidosis which is serious diabetes complication producing excess blood acids. Various biochemical reaction is reported for insulin effect on the impairment of tissue. Further the deficiency in insulin results in increased levels of fatty acids in plasma, lipolysis and a reduced glucose metabolism which results in deficiency of insulin for target tissues such as GLUT 4 class in adipose tissue, glucokinase in the liver. Hence these metabolic derangements result in diabetes [41].

TYPE-II DIABETES:

Type-II diabetes (NIDDM) is divided into following groups:

(i) DM with fasting hyperglycemia 
(ii) DM with minimal fasting hyperglycemia

(iii) Glucose tolerance (normal)

(iv) Impaired glucose tolerance

Individuals having with impaired glucose tolerance are insulin resistant. The levels of insulin decrease in NIDDM individuals. Resistance of insulin and deficiency are common in NIDDM individuals [42]. Transformation occurs in the Beta cells to increase insulin and compacting exceeds demand. Therefore, insulin secretion concentration is increased. MODY is an autosomal trait due to mutations in gene of glucokinase gene. Which is responsible for glucose metabolism mainly in liver and beta cells.

Various classes of drugs were developed to elevated the insulin such as thiazolidines. The bound and altered the PPARg receptor which is a transcription factor .IT when activated activates another receptor or transcription factor call RXR - retinoid $\mathrm{x}$ receptor. Which is key regulator for differentiation of adipocyte cells.it also help in synthesis of biological active compounds from endothelial cells as described in figure 1 [43].

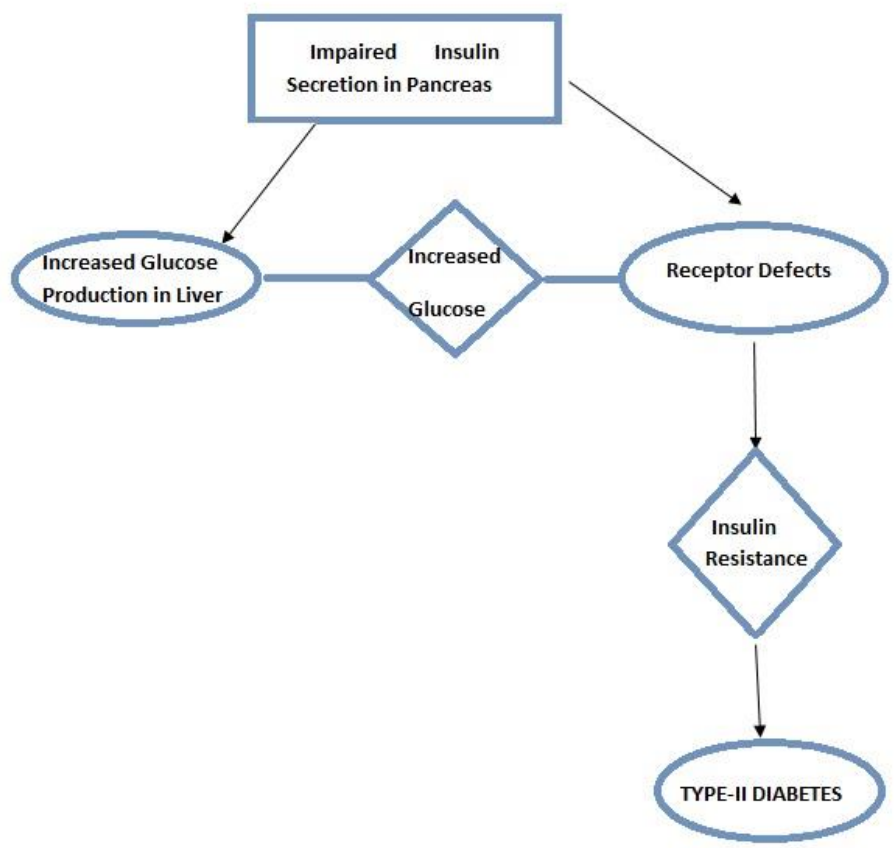

Figure 1: Pathophysiology of Type-II [43] 


\section{TREATMENT}

There is various treatment for diabetes available:

\subsection{DRUG TREATMENT:}

Diabetes - mellitus is treated by reducing the blood glucose levels. Oral hypoglycemic agents such as Pramlinitide, Exenatide are given orally. These drugs increase the level if insulin in beta cells as well as increase the sensitivity of organs for the glucose [44]. Some agents decrease the rate for the absorption of glucose in the gastro intestinal tract. Various formulations include:

(I) MEGLITINIDES

These are often referred as short - acting secretagogues which aid pancreas to secrete more of insulin. they act by channel regulation. They generally close the $\mathrm{K}^{+}$channels in the Beta cells, while opening $\mathrm{Ca}^{+}$elevating the secretion of insulin.

Examples: Nateglinide

(II) INSULIN

Usually insulin is given intravenously or by insulin pump. It is mainly used to treat type - I diabetes

(III) BIGUANIDES

They include drugs like Phenformin which reduce hepatic output of glucose and elevate the glucose uptake by the peripherals including muscles like skeletal muscle.

Other Examples : Buformin, Metformin

(IV) THIAZOLIDINES:

Commonly called as Glitazones are type of regulatory proteins. They bind to PPARy and are involved in genes wwhich regulate glucose mainly the transcription genes. They elevate the insulin secretion by enhancing the production of mRNA's of enzymes that are insulin dependent. Example: Troglitazone, Rosiglitazone.

PEPTIDE ANALOGS

(i) GLUCAGON - LIKE PEPTIDE (GLP)

GLP agonists tend to bind with GLP receptor. Insulin secretion is increased by the Beta cells. Example: Exenatide

(ii) INCRETIN MIMETICS: These are insulin secretagogues. 


\section{GASTRIC INHIBITORY PEPTIDE ANALOGS}

(i) AMYLIN ANALOGUES: These suppress glucagon and slow the rate of gastric emptying. They administer by subcutaneously.

\section{(II) DDP-4 INHIBITORS}

By inhibiting the dipeptidyl peptidase-4 incretin conc. In the blood [27].

\subsection{Reported bioactives for treatment of Diabetes:}

The various medicinal plants have been used as a dietary supplement from a long time and in the treatment of various diseases without the proper prescription of a qualified doctor. Although herbal therapy continues to be used in globally in many contourites, rare medicinal plants have gotten scientific and medical scrutiny. Moreover, a large number of medicinal plants retain some extent of toxicity. It is also proclaimed that one-third of medicinal plants used in the remedy of diabetic complications is examined to be toxic $[6,17]$. Since a long time, several plants are examined to be an alternative source of potent antidiabetic drugs and these herbal drugs getting more popularity among the peoples because they are examined to be lacking any side effects. It has been prophesied that more than 400 plants species and their secondary metabolites such as alkaloids, glycosides, terpenoids, flavonoids, carotenoids, tannins, and polyphenolic derivatives or derived products are being used for the treatment of diabetes mellitus and their complications [45, 46].

Following bioactive compounds and Herbs used for Treatment of Diabetes mellitus

\section{Gymnema sylvestre, Family: Asclepiadaceae}

Various evidences demonstrated that the leaves of G.sylvestre also known as Meshashringi, Kavali, Dhuleti, Gurmar can act as hypoglycemic agent for the treatment of diabetes. There were various studies conducted by different scientists which showed its action by decreasing the levels of FBG, PPBG \& HbA1c in type 2 diabetes when $400 \mathrm{mg}$ of the extract was taken per day for 1.5 years. The increase in the action of insulin was also observed [47-49].

Aegle marmelos, Family- Rutaceae 
It is also known as bael. According to a study conducted by Ismail(2009a), a significant reduction in PPBG was seen when patients were given $206 \pm 6 \mathrm{mg} / \mathrm{dl}$ were given decoction of $5 \mathrm{~g}$ A. marmelos leaf powder per day [50].

\section{Momordica charantia Family- Cucurbitaceae}

According to the studies, the dried powder consumption of $M$. charantia fruit led to decrease in the FBG in different diabetic patients. The aqueous \& alcoholic extracts of M.charantia also produced similar effect [51].

\section{Nigella sativa Family- Ranunculaceae}

Nigella sativa was appeared to altogether improve lab boundaries of hyperglycemia \& diabetes control after treatment with a huge fall in fasting blood glucose, blood glucose level $2 \mathrm{~h}$ postprandial, glycated haemoglobin, obstruction of insulin $\&$ an ascent in serum insulin [52].

\section{Panax quinquefolius, Family- Araliaceae}

These are the most preferable ginseng is found in America. According to different researches it has been found that this species led to the reduction in PPBG level when given to type 2 diabetic patients. The reduction in area under curve by $20 \%$ was observed when the patients were given $3 \mathrm{~g}$ of ginseng [53-54].

\section{Silybum marianum, Family- Asteraceae}

The seeds of Silybum marianum are found to be of great importance \& is highly beneficial in the disorders of the liver. The flavonolignans of $S$. marianum lead to the reduction in the level of the glucose $\&$ are therefore useful in the diabetic patients [55]. According to the clinical study, it has been observed that this species led to the reduction in HbA1c, FBG, TG, LDL, SGOT \& SGPT when given to the type 2 diabetes patients in the dose 200mg three times in a day [56].

\section{Salacia reticulate, Family- Celastraceae}

It has been observed that Salacia reticulate in the form of an aqueous extract was used in diabetes treatment. $240 \mathrm{mg}$ of the drug was given every day for 6 weeks \& it led to the reduction of Hb1c 
\& FBG levels in type 2 diabetes patients [57]. The same observations were reported when the patients were given Salacia reticulate tea for the period of 3 months [58].

Trigonella foenum-graecum, Family - Fabaceae

The seeds of Trigonella foenum-graecum popularly known as fenugreek seeds have been proved as effective hypoglycemic agent. There have been more than thirty studies done in animal models, cell cultures \& humans which show antidiabetic effect [59].100g of these seeds given regularly for 10 days to a diabetic patient may cause a significant decrease in TG, total cholesterol, FBG \& glucosourea. In another study, the same amount of seeds were soaked in hot water or were mixed in yoghurt. The results showed the reduction in VLDL, TG \& FBG when the soaked seeds were given to the patients with type 2 diabetes for 8 weeks [60].

\section{Allium cepa, Family- Amaryllidaceae}

It is popularly known as onion. It was reported by Mathew and Augusti in 1975 that when it is consumed orally may lead to improvement in the glycemic control. There effective antidiabetic property was studied when the patients with type $1 \&$ type 2 diabetes were given $100 \mathrm{~g}$ of A.cepa $\&$ also led to significant reduction in levels of FBG. The improvement in the glucose tolerance test (GTT) was also observed [61].

\section{Purslane portulaca oleracea, Family-Portulacaceae}

The extract of Pruslane Portulaca oleracae lowers blood glucose and the level of fasting glucose in diabetic patient. The studies were carried out in rats for observing tge antidiabetic activity. It was seen that when the rats were given the extract doses of $50,100 \& 200 \mathrm{mg} / \mathrm{kg}$ by the intraperitoneal route, there was a reduction in the serum glucose levels [62].

\section{Acacia arabica or nilotica, Family -Mimosaceae}

The powdered seeds of Acacia arabica mainly act by increasing insulin secretion in Beta cells of pancreas. This tree, discovered everywhere on the subcontinent yields a bountiful stock of gum. The decoction of its bark is utilized in loose bowels, diarrhea \& swishes for light gums [63].

Abelmoschus moschatus, Family- Malvaceae 
Aerial part generally lead to the enhancement in GLUT 4 and P13 Kinase insulin sensitivity is increased. According to the studies conducted in rats was found that the bolus IV injection of this species led to the decrease in the concentration of glucose in the plasma [64]. The area under curve of insulin \& glucose reduced the insulin tolerance during the glucose tolerance test by intraperitoneal route [65].

\section{Aloe barbadensis, Family- Asphodelaceae}

Leaves act by stimulating secretion of insulin from the beta cells. The oral administration of 500 $\mathrm{mg} / \mathrm{kg} \&$ administration of bitter principle interperitonially $5 \mathrm{mg} / \mathrm{kg}$ resulted in the hypoglycemic response of single oral dose. It was even administered 2 times $\&$ bitter principle was administered one time for 4 days in the chronic studies [66].

\section{Artemisia alba, Family-Asteraceae}

Aerial part generally containing sesquiterpene lactones cause significant decrease in blood sugar levels. It was reported by Al-Waili that the extract of this species which led to an important role in lowering the raised circulatory strain \& glucose levels in the blood, \& it additionally had antiarrythmic \& anxiolytic properties. Later on Ibrahim also led to the similar outcomes [67].

\section{Canavalia ensiformis DC, Family- Leguminosae}

Concentration of cholesterol, triacyl glycerol in plasma indicated antihyperlipidemic effect. When the aqueous extract of seeds of this species was administered orally for one week, it led to the significant reduction in hyperketonemia \& hyperlipidaemia in the rats with diabetes [68].

Psidium guajava, Family- Myrtaceae

Activity of hepatic hexokinase was increased and it was decreased by aqueous extract. An oral glucose tolerance test was carried out in long term feeding rats showed a significant reduction in the blood sugar level in diabetic rats fed with either the aqueous or ethanol extract of guava leaves [69].

The numbers of herbal plants have been used in the formulations to treat diabetes as shown in table 1 and the mechanism of action of medicinal plants explained in figure 2 . Their chemical structures 
shown in figure 3,4 and 5. they contain ingredients which are describes as an alternative to allopathic medicines as well as does not produce any side effects on the body.

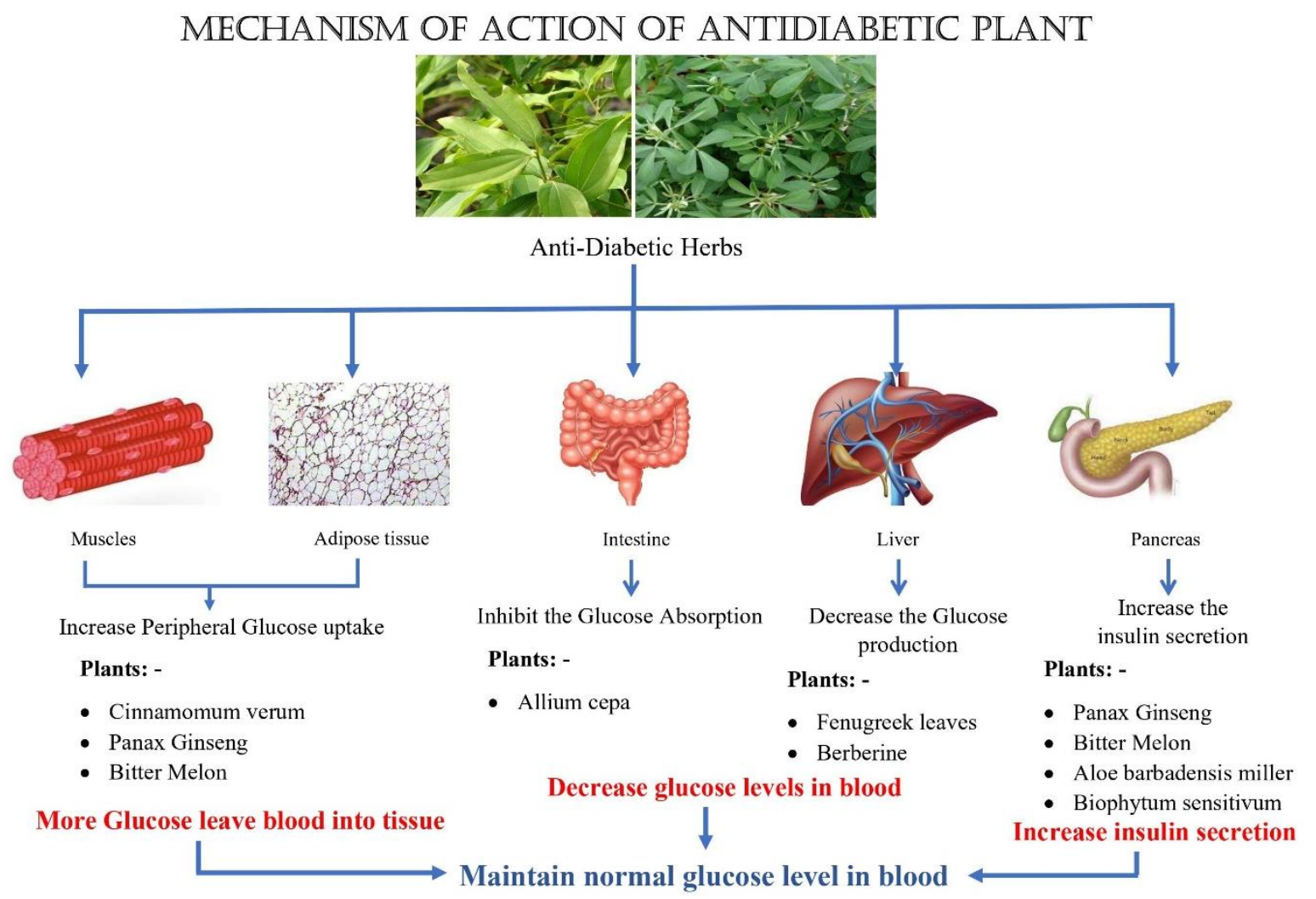

Figure 2: Mechanism of action of antidiabetic medicinal plants 
Table 1: Reported bioactive Compounds for treatment of diabetes

\begin{tabular}{|c|c|c|c|c|c|c|}
\hline S.NO & $\begin{array}{l}\text { Common } \\
\text { Name }\end{array}$ & $\begin{array}{l}\text { Botanical } \\
\text { Name }\end{array}$ & $\begin{array}{l}\text { Plant } \\
\text { Part } \\
\text { used } \\
\end{array}$ & $\begin{array}{l}\text { Major } \\
\text { Phytoconstituents }\end{array}$ & $\begin{array}{l}\text { Mechanism } \\
\text { of Action }\end{array}$ & $\begin{array}{l}\text { Referen } \\
\text { ce }\end{array}$ \\
\hline 1. & $\begin{array}{l}\text { Indian gum } \\
\text { Arabic } \\
\text { Tree/Babul/ } \\
\text { Kikar }\end{array}$ & $\begin{array}{l}\text { Acacia } \\
\text { arabica or } \\
\text { nilotica } \\
\text { Mimosaceae }\end{array}$ & $\begin{array}{l}\text { Powere } \\
\text { d seeds }\end{array}$ & $\begin{array}{l}\text { Contains arabin, a } \\
\text { mixture of salts of } \\
\text { Arabic acids of calcium, } \\
\text { magnesium and } \\
\text { potassium. }\end{array}$ & $\begin{array}{l}\text { Mainly act } \\
\text { by } \\
\text { increasing } \\
\text { insulin } \\
\text { secretion in } \\
\text { Beta cells of } \\
\text { pancreas. }\end{array}$ & [45] \\
\hline 2 & Aloe & $\begin{array}{l}\text { Aloe } \\
\text { barbadensis, } \\
\text { Asphodelace } \\
\text { ae }\end{array}$ & $\begin{array}{l}\text { Leaf, } \\
\text { powder }\end{array}$ & $\begin{array}{l}\text { glucomannans [beta- } \\
(1,4) \text {-acetylated } \\
\text { mannan }\end{array}$ & $\begin{array}{l}\text { Also act by } \\
\text { stimulating } \\
\text { secretion of } \\
\text { insulin from } \\
\text { the beta } \\
\text { cells. }\end{array}$ & [46] \\
\hline 3. & $\begin{array}{l}\text { Vegetable } \\
\text { Insulin/Bitter } \\
\text { melon }\end{array}$ & $\begin{array}{l}\text { Momocardia } \\
\text { charantia, } \mathrm{Cu} \\
\text { curbitaceae }\end{array}$ & $\begin{array}{l}\text { Seed } \\
\text { powder }\end{array}$ & $\begin{array}{l}\text { Charantine, Foetidin, } \\
\text { Cucurbitane }\end{array}$ & $\begin{array}{l}\text { Increase } \\
\text { insulin } \\
\text { sensitivity } \\
\text { and } \\
\text { signaling in } \\
\text { hfd induced } \\
\text { resistance }\end{array}$ & {$[47,48]$} \\
\hline 4. & $\begin{array}{l}\text { Okra, } \\
\text { Abelmosk, }\end{array}$ & $\begin{array}{l}\text { Abelmoschus } \\
\text { moschatus, } \mathrm{M} \\
\text { alvaceae }\end{array}$ & $\begin{array}{l}\text { Aerial } \\
\text { part }\end{array}$ & Mycricelin & $\begin{array}{l}\text { By } \\
\text { enhancemen } \\
\text { t in GLUT } 4 \\
\text { and P13 } \\
\text { Kinase } \\
\text { insulin } \\
\text { sensitivity is } \\
\text { increased. }\end{array}$ & {$[49,50]$} \\
\hline 5 & Bael & $\begin{array}{l}\text { Aegle } \\
\text { marmelose } \\
\text { (Rutaceae }\end{array}$ & Fruit & $\begin{array}{l}\text { Skimmianine, aegelin, } \\
\text { lupeol,cineole. }\end{array}$ & $\begin{array}{l}\text { Lowers } \\
\text { blood } \\
\text { glucose } \\
\text { level as well } \\
\text { as } \\
\text { hemoglobin } \\
\text { glycosylated } \\
\text { and increase } \\
\text { release of } \\
\text { insulin }\end{array}$ & {$[51,52]$} \\
\hline 6 & \begin{tabular}{l}
\multicolumn{2}{l}{$\begin{array}{l}\text { Cucumber } \\
\text { tress/ Tree } \\
\text { sorrel }\end{array}$} \\
\end{tabular} & $\begin{array}{l}\text { Averrhoa } \\
\text { bilimbi }\end{array}$ & Leaves & $\begin{array}{l}\text { cyanidin-3-O-h-D- } \\
\text { glucoside, phenolics, } \\
\text { potassium ion, sugars }\end{array}$ & $\begin{array}{l}\text { Increase in } \\
\text { insulin } \\
\text { secretion }\end{array}$ & {$[52,69]$} \\
\hline
\end{tabular}




\begin{tabular}{|c|c|c|c|c|c|c|}
\hline & & (Oxalidaceae & & & & \\
\hline 7 & Wormwood & $\begin{array}{l}\text { Artemisia } \\
\text { herba alba } \\
\text { (Asteraceae }\end{array}$ & $\begin{array}{l}\text { Aerial } \\
\text { part }\end{array}$ & Sesquiterpene lactones & $\begin{array}{l}\text { Cause } \\
\text { significant } \\
\text { decrease in } \\
\text { blood sugar } \\
\text { levels. }\end{array}$ & [70] \\
\hline 8 & $\begin{array}{l}\text { Chinese snake } \\
\text { gourd }\end{array}$ & $\begin{array}{l}\text { Trichosanthe } \\
\text { s kirilowii }\end{array}$ & Root & Trichosanthin & $\begin{array}{l}\text { Stimulate } \\
\text { the D- } \\
\text { glucose into } \\
\text { lipids }\end{array}$ & [71] \\
\hline 9 & Purslane & $\begin{array}{l}\text { Portulaca } \\
\text { oleracea } \\
\text { extract }\end{array}$ & Seeds & kaempferol, luteolin, & $\begin{array}{l}\text { Lowers } \\
\text { blood } \\
\text { glucose and } \\
\text { the level of } \\
\text { fasting } \\
\text { glucose in } \\
\text { diabetic } \\
\text { patient }\end{array}$ & {$[72,73]$} \\
\hline 10 & $\begin{array}{l}\text { Tree } \\
\text { Spinach/Chaya }\end{array}$ & $\begin{array}{l}\text { Cnidoscolus } \\
\text { aconitifolius }\end{array}$ & Leaves & $\begin{array}{l}\text { n-Hexadecenoic acid; } \\
\text { 9-Octadecenoic acid }\end{array}$ & $\begin{array}{l}\text { Considerabl } \\
\text { e decrease in } \\
\text { blood } \\
\text { glucose and } \\
\text { cholesterol } \\
\text { levels }\end{array}$ & {$[74,75]$} \\
\hline 11. & Neem & $\begin{array}{l}\text { Azadirachta } \\
\text { indica } \\
\text { (Meliaceae) }\end{array}$ & $\begin{array}{l}\text { Leaves, } \\
\text { seeds\& } \\
\text { bark }\end{array}$ & $\begin{array}{l}\text { tetranortriterpenoids, } \\
\text { pentanortriterpenoids, } \\
\text { hexanortriterpenoids }\end{array}$ & $\begin{array}{l}\text { Reduced } \\
\text { level of } \\
\text { glucose not } \\
\text { significantly } \\
\text { known }\end{array}$ & [76] \\
\hline 12. & Maachi Patram & $\begin{array}{l}\text { Artemisia } \\
\text { pallen, } \\
\text { Atemisia }\end{array}$ & $\begin{array}{l}\text { Aerial } \\
\text { part }\end{array}$ & Germacranolide & $\begin{array}{l}\text { Glucosse } \\
\text { utilization in } \\
\text { peripheral } \\
\text { part is } \\
\text { increased } \\
\text { and } \\
\text { decreased } \\
\text { reabsorption } \\
\text { of glucose in } \\
\text { the PCT of } \\
\text { the renal } \\
\text { tubules. }\end{array}$ & [77] \\
\hline
\end{tabular}




\begin{tabular}{|c|c|c|c|c|c|c|}
\hline 13. & $\begin{array}{l}\text { Betel } \\
\text { Palm/Areca } \\
\text { Nut }\end{array}$ & $\begin{array}{l}\text { Areca } \\
\text { catechu } \\
\text { (Arecaceae }\end{array}$ & $\begin{array}{l}\text { Powere } \\
\text { d leaves }\end{array}$ & Arecaidine, arecoline & $\begin{array}{l}\text { Reduced } \\
\text { hypoglycem } \\
\text { ic effect }\end{array}$ & {$[78,79]$} \\
\hline 14. & Punarnava & $\begin{array}{l}\text { Boerhaavia } \\
\text { diffusa Linn. } \\
\text { (Nyctaginace } \\
\text { ae): }\end{array}$ & $\begin{array}{l}\text { Whole } \\
\text { plant, } \\
\text { root, } \\
\text { and leaf }\end{array}$ & $\begin{array}{l}\text { Punarnavine, } \quad \beta- \\
\text { Sitosterol }\end{array}$ & $\begin{array}{l}\text { Control of } \\
\text { glycosylated } \\
\text { hemoglobin }\end{array}$ & {$[80,81]$} \\
\hline 15 & $\begin{array}{ll}\text { Little } & \text { Tree } \\
\text { Plant, } & \end{array}$ & $\begin{array}{l}\text { Biophytum } \\
\text { sensitivum } \\
\text { (Oxalidaceae }\end{array}$ & $\begin{array}{l}\text { Whole } \\
\text { plant }\end{array}$ & $\begin{array}{l}\text { Amentoflavone, } \\
\text { Isoorientin }\end{array}$ & $\begin{array}{l}\text { Due to } \\
\text { release of } \\
\text { beta cells in } \\
\text { langerhans } \\
\text { which } \\
\text { stimulate } \\
\text { insulin }\end{array}$ & {$[82,83]$} \\
\hline 16 & Orchid tree & $\begin{array}{l}\text { Bauhinia } \\
\text { candicans } \\
\text { (Leguminosa } \\
\mathrm{e}\end{array}$ & Leaves & $\begin{array}{l}\text { Alpha- } \\
\text { occidental }\end{array}$ & $\begin{array}{l}\text { Peripheral } \\
\text { metabolism } \\
\text { of glucose is } \\
\text { increased. }\end{array}$ & [84] \\
\hline 17 & $\begin{array}{l}\text { Achiote, } \\
\text { Anatto }\end{array}$ & $\begin{array}{l}\text { Bixa orellana } \\
\text { (Bixaceae }\end{array}$ & seeds & Bixin & $\begin{array}{l}\text { Reduces } \\
\text { postprandial } \\
\text { increase in } \\
\text { blood } \\
\text { glucose. }\end{array}$ & [85] \\
\hline 18 & Black mustard & $\begin{array}{l}\text { Brassica } \\
\text { nigra L L } \\
\text { (Brassicaceae }\end{array}$ & Seed & $\begin{array}{l}\text { Glycerides of stearic } \\
\text { and oleic acid }\end{array}$ & $\begin{array}{l}\text { Insulinotrop } \\
\text { ic effect }\end{array}$ & [86] \\
\hline 19 & Wild Hop & $\begin{array}{l}\text { Bryonia alba } \\
\text { (Cucurbitace } \\
\text { ae) }\end{array}$ & Roots & Bryonin, hydrobryotin & $\begin{array}{lr}\text { Lower } & \text { the } \\
\text { effect } & \text { of } \\
\text { alpha } & \\
\text { amylase } & \end{array}$ & [87] \\
\hline 20 & & $\begin{array}{l}\text { Bridelia } \\
\text { ndellensis } \\
\text { Beille. } \\
\text { (Euphorbiace } \\
\text { ae }\end{array}$ & $\begin{array}{l}\text { Stem } \\
\text { bark }\end{array}$ & $\begin{array}{l}\text { ethyl acetate } \\
\text { dichloromethane }\end{array}$ & $\begin{array}{l}\text { Only } \\
\text { decreased } \\
\text { glucose } \\
\text { level in the } \\
\text { blood }\end{array}$ & [88] \\
\hline 21 & $\begin{array}{l}\text { Great } \\
\text { Bougainvillea }\end{array}$ & $\begin{array}{l}\text { Bougainville } \\
\text { a spectabilis } \\
\text { Linn. } \\
\text { (Nyctaginace } \\
\text { ae }\end{array}$ & $\begin{array}{l}\text { Stem } \\
\text { Bark }\end{array}$ & $\begin{array}{l}\text { Alpha ionone, alpha } \\
\text { copaene }\end{array}$ & $\begin{array}{l}\text { Antiglycemi } \\
\text { c }\end{array}$ & [89] \\
\hline
\end{tabular}




\begin{tabular}{|c|c|c|c|c|c|c|}
\hline 22 & Ivy Gourd & $\begin{array}{l}\text { Coccinia } \\
\text { indica Wight } \\
\& \quad \text { Arn. } \\
\text { (Cucurbitace } \\
\text { ae }\end{array}$ & $\begin{array}{l}\text { Fruits } \\
\text { and } \\
\text { leaves }\end{array}$ & $\begin{array}{l}\text { Glucose,gum,carbonic } \\
\text { acid }\end{array}$ & $\begin{array}{l}\text { Insulin like } \\
\text { activity }\end{array}$ & [90] \\
\hline 23 & $\begin{array}{l}\text { Madagascar } \\
\text { periwinkle }\end{array}$ & $\begin{array}{l}\text { Catharanthus } \\
\text { roseus Linn. } \\
\text { (Apocyaceae }\end{array}$ & $\begin{array}{l}\text { Leaf } \\
\text { powder }\end{array}$ & $\begin{array}{l}\text { linolenic acid ethyl } \\
\text { ester }\end{array}$ & $\begin{array}{l}\text { Plasma } \\
\text { levels in } \\
\text { C+CR group } \\
\text { showed } \\
\text { antiglycemi } \\
\text { c activity }\end{array}$ & [91] \\
\hline 24 & Jack bean & $\begin{array}{l}\text { Canavalia } \\
\text { ensiformis } \\
\text { DC. } \\
\text { (Leguminosa } \\
\text { e }\end{array}$ & seeds & Prteins, phospholipids & $\begin{array}{l}\text { Concentrati } \\
\text { on of } \\
\text { cholesterol, } \\
\text { triacyl } \\
\text { glycerol in } \\
\text { plasma } \\
\text { indiacted } \\
\text { antihyperlipi } \\
\text { demic effect }\end{array}$ & [92] \\
\hline 25 & Coffee senna & $\begin{array}{l}\text { Cassia kleinii } \\
\text { Wight \& Arn. } \\
\text { (Caesalpiniac } \\
\text { eae }\end{array}$ & leaves, & Chrysophanol,emodin & $\begin{array}{l}\text { Decreased } \\
\text { glycogen } \\
\text { level, body } \\
\text { weight }\end{array}$ & [93] \\
\hline 26 & $\begin{array}{l}\text { Myrobalan,har } \\
\text { ad }\end{array}$ & $\begin{array}{l}\text { Terminalia } \\
\text { chebula Retz. } \\
\text { (Combretace } \\
\text { ae) }\end{array}$ & fruits & Coumarin & $\begin{array}{l}\text { Decrease in } \\
\text { glycosylated } \\
\mathrm{B} \text { and } \\
\text { increase in } \\
\text { total } \\
\text { haemoglobi } \\
\mathrm{n} \text { in diabetic } \\
\text { rats }\end{array}$ & [94] \\
\hline 27 & Asian ginseng & $\begin{array}{l}\text { Panax } \\
\text { ginseng, } \\
\text { Araliaceae }\end{array}$ & $\begin{array}{l}\text { Roots } \\
\text { and } \\
\text { rhizom } \\
\text { es }\end{array}$ & Ginsenoside & $\begin{array}{l}\text { Serum } \\
\text { insulin is } \\
\text { reduced }\end{array}$ & [95] \\
\hline
\end{tabular}




\begin{tabular}{|c|c|c|c|c|c|c|}
\hline 28 & Aloe & $\begin{array}{l}\text { Aloe } \\
\text { vera(Asphod } \\
\text { elaceae) }\end{array}$ & leaves & Aloin & $\begin{array}{l}\text { Levels of } \\
\text { fasting } \\
\text { glucose is } \\
\text { reduced }\end{array}$ & [96] \\
\hline 29 & Sugar apple & $\begin{array}{l}\text { Annona } \\
\text { squamosa } \\
\text { Linn. } \\
\text { (Annonaceae }\end{array}$ & seeds & Squamocenin & $\begin{array}{l}\text { Improves } \\
\text { plasma } \\
\text { insulin }\end{array}$ & [97] \\
\hline 30 & Milkvetch & $\begin{array}{l}\text { Astragalus } \\
\text { membranace } \\
\text { us (Fisch.) } \\
\text { (Fabaceae }\end{array}$ & root & Astragaloside & $\begin{array}{l}\text { Protection } \\
\text { of } \\
\text { pancreatic } \\
\text { cells from } \\
\text { cell death } \\
\text { and decrease } \\
\text { onset of } \\
\text { diabetes. }\end{array}$ & [98] \\
\hline 31 & Grey Nicker & $\begin{array}{l}\text { Caesalpinia } \\
\text { bonducella } \\
\text { (Fabaceae): }\end{array}$ & seeds & $\begin{array}{l}\text { Caesalpinin, } \\
\text { Bonducellin }\end{array}$ & $\begin{array}{l}\text { Potent } \\
\text { activity of } \\
\text { hypoglycem } \\
\text { ia }\end{array}$ & {$[99,100]$} \\
\hline 32 & Karira & $\begin{array}{l}\text { Capparis } \\
\text { deciduas, } \\
\text { Capparacae }\end{array}$ & $\begin{array}{l}\text { Aerial } \\
\text { parts }\end{array}$ & $\begin{array}{l}\text { Isocodonocarpine, } \\
\text { Capparisinine }\end{array}$ & $\begin{array}{l}\text { Inhibition of } \\
\text { alpha } \\
\text { amylase }\end{array}$ & [101] \\
\hline 34 & Broom creeper & $\begin{array}{l}\text { Cocculus } \\
\text { hirstus, } \\
\text { Menispermac } \\
\text { ae }\end{array}$ & Leaves & Coclaurine,Triobine & $\begin{array}{l}\text { Serum level } \\
\text { of glucose is } \\
\text { lowered. }\end{array}$ & [102] \\
\hline 35 & Bitter yam & $\begin{array}{l}\text { Dioscorea } \\
\text { dumetorum } \\
\text { Pax. }\end{array}$ & Tuber & Tryptophan,threonine & $\begin{array}{l}\text { Decreased } \\
\text { blood conc. } \\
\text { of }\end{array}$ & [103] \\
\hline
\end{tabular}




\begin{tabular}{|c|c|c|c|c|c|c|}
\hline & & $\begin{array}{l}\text { (Dioscoreace } \\
\text { ae }\end{array}$ & & & $\begin{array}{l}\text { glucose,bod } \\
\text { y weight and } \\
\text { conc. of } \\
\text { insulin }\end{array}$ & \\
\hline 36 & Pitanga & $\begin{array}{l}\text { Eugenia } \\
\text { uniflora, } \\
\text { Myrtaceae }\end{array}$ & Leaves & Atractylone, curzerene & $\begin{array}{l}\text { Inhibit level } \\
\text { of } \\
\text { triglycerides }\end{array}$ & [104] \\
\hline 37 & Elephant Foot & $\begin{array}{l}\text { Elephantopus } \\
\text { scaber,Astera } \\
\text { ceae }\end{array}$ & $\begin{array}{l}\text { Leaves } \\
\text { and } \\
\text { roots }\end{array}$ & $\begin{array}{lr}\text { hexadecanoic } & \text { acid, } \\
\text { isopropyl dimethyl } \\
\text { tetrahydronaphthalenol }\end{array}$ & $\begin{array}{l}\text { Positive } \\
\text { control on } \\
\text { diabetic } \\
\text { activity }\end{array}$ & [105] \\
\hline 38 & Indian banyan & $\begin{array}{l}\text { Ficus } \\
\text { bengalenesis }\end{array}$ & $\begin{array}{l}\text { Aerial } \\
\text { roots }\end{array}$ & $\begin{array}{l}\text { beta-sitosterol-alpha-D- } \\
\text { glucose }\end{array}$ & Fall in BGL & [106] \\
\hline 39 & Bitter kola & $\begin{array}{l}\text { Garcinia kola } \\
\text { (Clusiaceae) }\end{array}$ & Seeds & Kolaviron & $\begin{array}{l}\text { Reduced } \\
\text { level of } \\
\text { glucose }\end{array}$ & [107] \\
\hline 40 & $\begin{array}{l}\text { Chinese } \\
\text { Foxglove }\end{array}$ & $\begin{array}{l}\text { Rehmanniae } \\
\text { Radix, } \\
\text { Orobanchace } \\
\text { ae }\end{array}$ & Root & Catapol, vit A, B, C, D. & $\begin{array}{l}\text { Inhibit } \\
\text { diabetic } \\
\text { nephropathy }\end{array}$ & [108] \\
\hline 41 & Chinese cassia & $\begin{array}{l}\text { Cinnamomи } \\
\text { m cassia, } \\
\text { Lauraceae }\end{array}$ & bark & Cinnamaldehyde & $\begin{array}{l}\text { inhibit } \\
\text { fibronectin }\end{array}$ & [109] \\
\hline 42 & Malabar kino & $\begin{array}{l}\text { Pterocarpus } \\
\text { marsupium,F } \\
\text { abaceae }\end{array}$ & Wood & $\begin{array}{l}\text { Liquiritigenin, } \\
\text { isoliquiritigenin }\end{array}$ & $\begin{array}{l}\text { Regenerate } \\
\text { Beta cells of } \\
\text { pancreas }\end{array}$ & [110] \\
\hline
\end{tabular}




\begin{tabular}{|c|c|c|c|c|c|c|}
\hline 43 & Fenugreek & $\begin{array}{l}\text { Trigonella } \\
\text { foenum- } \\
\text { graecum, } \\
\text { Fabaceae }\end{array}$ & $\begin{array}{l}\text { Seed } \\
\text { Extract }\end{array}$ & $\begin{array}{l}\text { kaempferol 3-O- } \beta-d- \\
\text { glucopyranoside. }\end{array}$ & $\begin{array}{l}\text { Decreased } \\
\text { absorption } \\
\text { of glucose }\end{array}$ & [111] \\
\hline 44 & $\begin{array}{l}\text { Korean } \\
\text { angelica-tree }\end{array}$ & $\begin{array}{l}\text { Aralia elata, } \\
\text { Araliaceae }\end{array}$ & Seeds & $\begin{array}{l}\text { Silphioside } \\
\text { araloside A,C,D }\end{array}$ & $\begin{array}{l}\text { Inhibitory of } \\
\text { intenstinal } \\
\text { alpha- } \\
\text { glucosidase. }\end{array}$ & [112] \\
\hline 45 & Guar & $\begin{array}{l}\text { Cyamopsis } \\
\text { tetragonolob } \\
a\end{array}$ & $\begin{array}{l}\text { Leaves, } \\
\text { seeds }\end{array}$ & $\begin{array}{l}\text { P-hydroxycinamyl, } \\
\text { astragalin. }\end{array}$ & $\begin{array}{l}\text { Lowering } \\
\text { of lipid and } \\
\text { blood sugar }\end{array}$ & [113] \\
\hline 46 & $\begin{array}{l}\text { Chinese } \\
\text { goldthread }\end{array}$ & $\begin{array}{l}\text { Coptis } \\
\text { chinensis, } \\
\text { Ranunculace } \\
\text { ae }\end{array}$ & Roots & Berberine, Palmatine & $\begin{array}{l}\text { CCPW-1 } \\
\text { inhibited the } \\
\text { blood } \\
\text { glucose } \\
\text { level }\end{array}$ & [114] \\
\hline 47 & Alfalfa & $\begin{array}{l}\text { Medicago } \\
\text { sativa, } \\
\text { Fabaceae }\end{array}$ & Seeds & Stachydrine, betaine & $\begin{array}{l}\text { Beta cells } \\
\text { are } \\
\text { regenerated } \\
\text { and } \\
\text { increased } \\
\text { senstivity }\end{array}$ & [115] \\
\hline 48 & Henna & $\begin{array}{l}\text { Lawsonia } \\
\text { inermis, } \\
\text { Lythraceae }\end{array}$ & $\begin{array}{l}\text { Whole } \\
\text { Plant }\end{array}$ & hennotannic acid & $\begin{array}{l}\text { Ethanolic } \\
\text { extract } \\
\text { reduced } \\
\text { diabetes and } \\
\text { had } \\
\text { antidiabetic } \\
\text { effect }\end{array}$ & [116] \\
\hline
\end{tabular}




\begin{tabular}{|c|c|c|c|c|c|c|}
\hline 49 & $\begin{array}{l}\text { Common } \\
\text { guava }\end{array}$ & $\begin{array}{l}\text { Psidium } \\
\text { guajava,Myrt } \\
\text { aceae }\end{array}$ & Leaves & guajanoic acid, uvao & $\begin{array}{l}\text { Activity of } \\
\text { hepatic } \\
\text { hexokinase } \\
\text { was } \\
\text { increased } \\
\text { and it was } \\
\text { decreased } \\
\text { by aqueous } \\
\text { extract }\end{array}$ & [117] \\
\hline 50 & $\begin{array}{l}\text { Heart-leaved } \\
\text { moonseed }\end{array}$ & $\begin{array}{l}\text { Tinospora } \\
\text { cordifolia,Me } \\
\text { nispermaceae }\end{array}$ & $\begin{array}{l}\text { Stem } \\
\text { Bark }\end{array}$ & $\begin{array}{l}\text { Columbin, } \\
\text { tinosporaside }\end{array}$ & $\begin{array}{l}\text { Prevent } \\
\text { Hyperalgesi } \\
\text { a in diabetic } \\
\text { neuropathy }\end{array}$ & [118] \\
\hline 51 & Ginger & $\begin{array}{l}\text { Zingiber } \\
\text { officinale,Zin } \\
\text { giberaceae }\end{array}$ & $\begin{array}{l}\text { Rhizom } \\
\text { es }\end{array}$ & Zingerone,gingerols & $\begin{array}{l}\text { Improved } \\
\text { PON-1 And } \\
\text { TAC } \\
\text { activity in } \\
\text { diabetes } \\
\text { patients }\end{array}$ & [119] \\
\hline 52 & Java grass & $\begin{array}{l}\text { Cyperus } \\
\text { rotundus, } \\
\text { Cyperaceae }\end{array}$ & $\begin{array}{l}\text { Rhizom } \\
\text { es }\end{array}$ & Iridoids & $\begin{array}{l}\text { Serum } \\
\text { triglycerides } \\
\text { were } \\
\text { reduced }\end{array}$ & [120] \\
\hline 53 & Quince & $\begin{array}{l}\text { Cydonia } \\
\text { oblonga, } \\
\text { Rosaceae }\end{array}$ & Seeds & Cyprene, Mustakone & $\begin{array}{l}\text { Lowered } \\
\text { lipid levels }\end{array}$ & [121] \\
\hline 54 & Butterfly pea & $\begin{array}{l}\text { Clitoria } \\
\text { ternatea, } \\
\text { Fabaceae }\end{array}$ & $\begin{array}{l}\text { Leaves } \\
\text { and } \\
\text { Flowers }\end{array}$ & Cliotides,steroids & $\begin{array}{l}\text { Decreased } \\
\text { glycosylated } \\
\text { levels }\end{array}$ & {$[122]$} \\
\hline
\end{tabular}




\begin{tabular}{|c|c|c|c|c|c|c|}
\hline 55 & Star flower & $\begin{array}{l}\text { Hypoxis } \\
\text { hemerocallid } \\
\text { ea, } \\
\text { Hypoxidacea } \\
\mathrm{e}\end{array}$ & $\begin{array}{l}\text { Rhizom } \\
\text { es }\end{array}$ & pentenyne glycoside & $\begin{array}{l}\text { Hypoglyce } \\
\text { mic activity }\end{array}$ & [123] \\
\hline 56 & $\begin{array}{l}\text { Common } \\
\text { Agrimony }\end{array}$ & $\begin{array}{l}\text { Agrimony } \\
\text { eupatoria, } \\
\text { Rosaceae }\end{array}$ & $\begin{array}{l}\text { Aerial } \\
\text { part }\end{array}$ & Volatile oils & $\begin{array}{l}\text { Insulin like } \\
\text { activity }\end{array}$ & [124] \\
\hline 57 & Pigeon pea & $\begin{array}{l}\text { Cajanus } \\
\text { cajan } \\
\text { (Fabaceae) }\end{array}$ & Leaves & Cajanin & $\begin{array}{l}\beta \text {-cells of } \\
\text { Islets of } \\
\text { Langerhan } \\
\text { were } \\
\text { developed }\end{array}$ & [125] \\
\hline 58 & Teripod & $\begin{array}{l}\text { Caesalpinia } \\
\text { digyna, } \\
\text { Fabaceae }\end{array}$ & root & Tannins, bonducin & $\begin{array}{l}\text { Glycogen } \\
\text { storage } \\
\text { increased }\end{array}$ & [126] \\
\hline 59 & Avacado & $\begin{array}{l}\text { Persea } \\
\text { Americana, } \\
\text { Lauraceae }\end{array}$ & Fruit & Vitamin, Minerals & $\begin{array}{l}\text { Glucose } \\
\text { uptake in } \\
\text { liver is } \\
\text { regulated }\end{array}$ & [126] \\
\hline 60 & Bilberry & $\begin{array}{l}\text { Vaccinium } \\
\text { myrtillus, } \\
\text { Ericaceae }\end{array}$ & $\begin{array}{l}\text { Leaf, } \\
\text { Fruit }\end{array}$ & Anthocyanoside & $\begin{array}{l}\text { Prevention } \\
\text { of HDL- C, } \\
\text { LDL,VLDL }\end{array}$ & [127] \\
\hline
\end{tabular}


<smiles>OCC1OC(OC2C(CO)OC(OC3C(CO)OC(OC4C(CO)OC(O)C(O)C4O)C(O)C3O)C(O)C2O)C(O)C(O)C1O</smiles>

Glucomannans [beta-(1,4)-acetylated mannan<smiles>CCC(CC(C)C)CC(C)C1CCC2C3CC=C4CC(OC5OC(CO)C(O)C(O)C5O)CCC4(C)C3CCC12C</smiles>

Charantin<smiles>C=C1CCC2C(C)(C)C(O)CCC2(C)C1COc1cc(=O)oc2ccccc12</smiles>

Foetidin<smiles>C=C(C)C1CCC2(C)CCC3(C)C(CCC4C5(C)CCC(O)C(C)(C)C5CCC43C)C12</smiles>

Lupeol<smiles>O=c1c(O)c(-c2ccc(O)cc2)oc2cc(O)cc(O)c12</smiles>

Kaempferol<smiles></smiles>

Germacranolide<smiles>CC(C)CCCC(C)C1CCC2(C)C1CCC1(C)C3CCCC(C)(C)C3CCC21C</smiles>

Cucurbitane<smiles>COc1ccc2c(OC)c3ccoc3nc2c1OC</smiles>

Skimmianine<smiles>COc1ccc(C(O)CNC(=O)/C=C/c2ccccc2)cc1</smiles>

Aegeline<smiles>CC12CCC(C1)C(C)(C)OC2</smiles>

Cineole

cyanidin-3-O-h-D-glucoside<smiles>CC=C(C)C(=O)OC1CC(C)(O)C2CC=C(C)C2C2OC(=O)C(OC(C)=O)(OC(C)=O)C12</smiles>

Sesquiterpene lactone<smiles>O=c1cc(-c2ccc(O)c(O)c2)oc2cc(O)cc(O)c12</smiles>

Luteolin<smiles>CCCCC(=O)O</smiles>

$\mathrm{n}$-Hexadecanoic acid

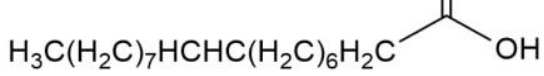

9-Octadecenoic acid<smiles>CN1CCC=C(C(=O)O)C1</smiles>

Arecaidine<smiles>COC(=O)C1=CCCN(C)C1</smiles>

Arecoline

Figure 3: Chemical structures of bioactive compounds 
<smiles>COc1ccc2c(=O)cc(-c3ccc4c(c3)OCO4)n(C)c2c1</smiles>

Punarnavine

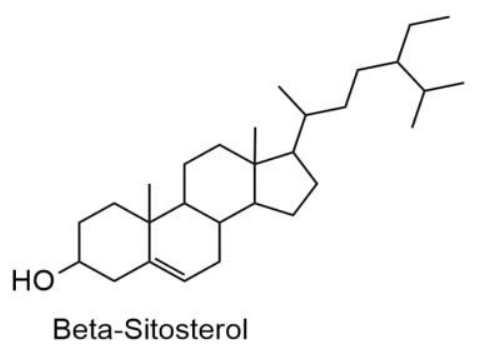

Beta-Sitosterol<smiles>CCCCCCCCCCOc1ccc(-c2cc(=O)c3c(O)cc(O)cc3o2)cc1-c1c(O)cc(O)c2c(=O)cc(-c3ccc(O)cc3)oc12</smiles><smiles>CC1=CC2CC1C(C)(C)C2C</smiles>

Isoorientin<smiles>CC(=O)/C=C/C1C(C)=CCCC1(C)C</smiles>

alpha-lonone<smiles>Cc1cc(O)c2c(c1)C(=O)c1cccc(O)c1C2=O</smiles>

Chrysophanol alpha-Pinene

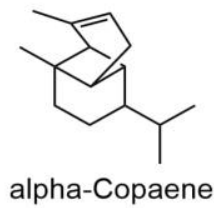

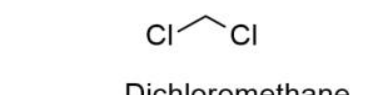

Dichloromethane<smiles>COC(=O)/C=C/C(C)=C/C=C/C(C)=C/C=C/C=C(C)/C=C/C=C(C)/C=C/C(=O)O</smiles>

Bixin<smiles>CC/C=C/C/C=C/C/C=C/CCCCCCCC(=O)OCC</smiles>
Linolenic acid, ethyl ester<smiles>Cc1cc(O)c2c(c1)C(=O)c1cc(O)cc(O)c1C2=O</smiles><smiles>O=c1ccc2ccccc2o1</smiles>

Coumarin

Emodin<smiles>COc1ccc(C=C2COc3cc(O)ccc3C2=O)cc1</smiles>

Bonducellin<smiles>NC(Cc1c[nH]c2ccccc12)C(=O)O</smiles>

Tryptophan

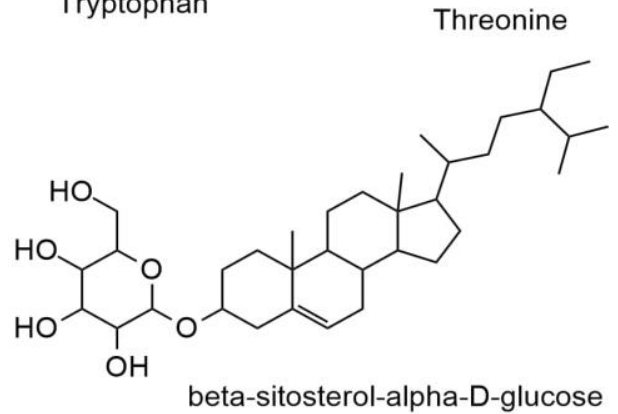<smiles>CNCCCCNC(=O)/C=C/CCOC</smiles><smiles>C1CCCCCC1</smiles><smiles>CCCNC=O</smiles><smiles>C=COc1cc(CC)ccc1O</smiles>

Capparisinine<smiles>C=CC1(C)Cc2occ(C)c2CC1C(=C)C</smiles>

Curzerene<smiles>OCC1OC(OC2OC=CC3C(O)C4OC24C3CO)C(O)C(O)C1O</smiles>

Catalpol<smiles>O=C1c2c(O)cccc2C(C2OC(CO)C(O)C(O)C2O)c2cc(CO)cc(O)c21</smiles>

Aloin A<smiles>COc1cc2c(cc1O)C(Cc1ccc(O)cc1)NCC2</smiles>

Coclaurine

Figure 4: Chemical structures of bioactive compounds 


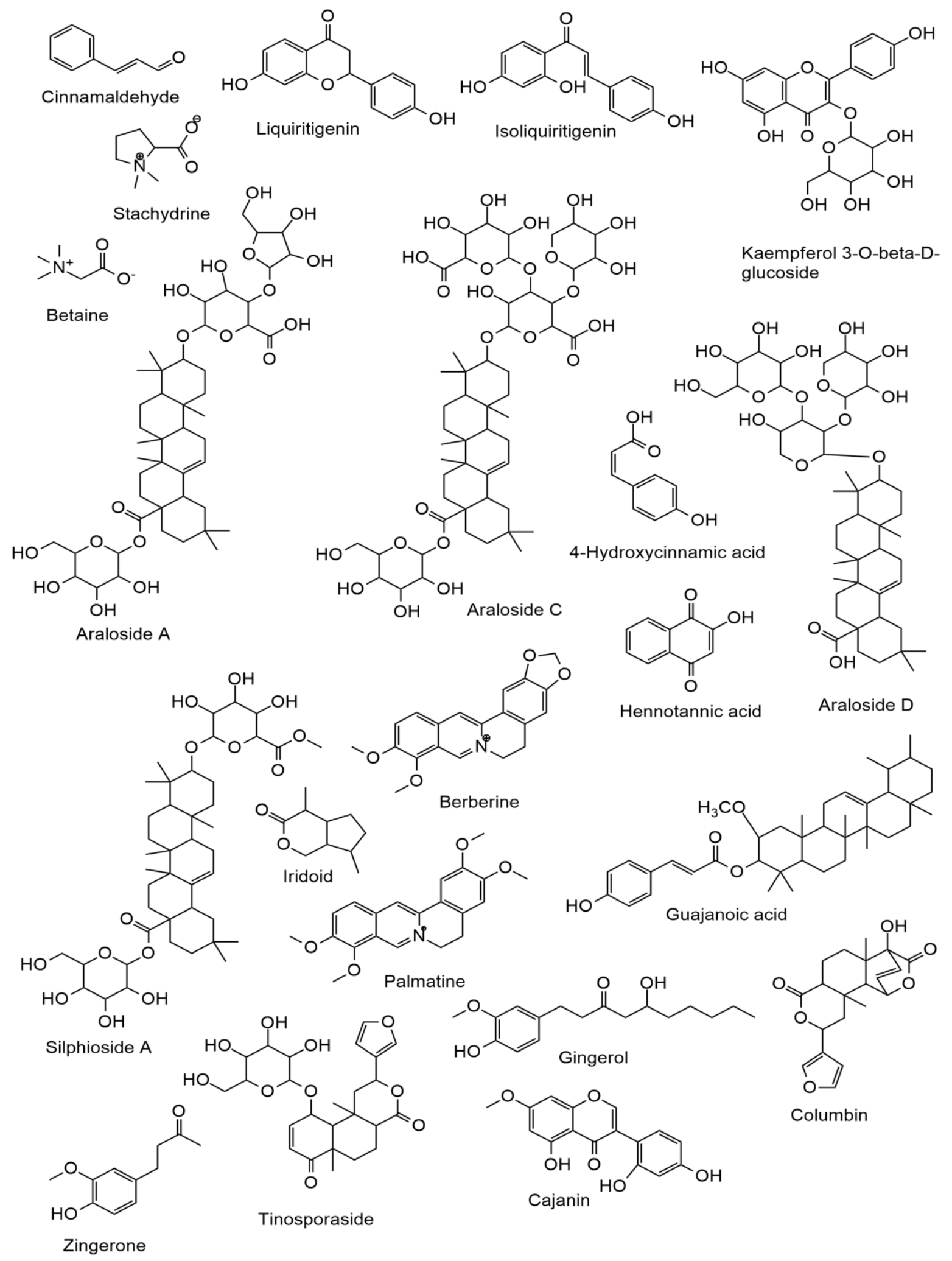

Figure 5: Chemical structures of bioactive compounds 


\section{CONCLUSION:}

Diabetes has been reported as the fastest growing disorder in the recent years. It has been reported to be associated with co- morbidities and hyper lipidemia like hypertension. Herbal drugs are beneficial to diabetes management. They possess very minimum side effects with maximum potency. Theses herbal drugs help in reducing glucose levels in the blood. Various mechanism possesses the antidiabetic properties. The drugs are describing on the basis of common names, part used, chemical constituents and mechanism of actions. Therefore, herbal plants play a very important role in the traditional medicine system.

\section{Funding}

None.

\section{Conflict of interest}

The authors declare no conflict of interest, financial or otherwise.

\section{Acknowledgements}

The authors are grateful to Dr. Madhu Chitkara, Pro Chancellor, Chitkara University, Rajpura, Patiala, India and Dr. Ashok Chitkara, Chancellor, Chitkara University, Rajpura, Patiala, India, for support and institutional facilities.

\section{References:}

1. Kumar PJ, Clark M. Textbook of Clinical Medicine. Pub: Saunders (London), pp 1099-1121, 2002.

2. Expert Committee on the Diagnosis and Classification of Diabetes Mellitus. Report of the expert committee on the diagnosis and classification of Diabetes Mellitus. Diabetes Care 1997; 20: $1183-1197$.

3. Malecki, M.T.; Klupa, T. Type 2 diabetes mellitus: from genes to disease. Pharmacol Rep. $2005,57,20-32$.

4. Kingh, H.; Aubert, R.E.; Herman, W.H. Global burden of diabetes, 1995-2025: prevalence, numerical estimates and projections. Diabetes care 1998;21(9):1414-1431.

5. WHO.2011 [cited 2011;Available from http://www.who.int/diabetes/en/. 
6. Kaul, K.; Tarr J.M.; Ahmad S.I.; Chibber R. Introduction to Diabetes Mellitus; advances in experimental Medicine and Biology ;771:1-11,2012.

7. Wallace, C.; Reiber, G.E.; LeMaster, J.; Smith, D.G.; Sullivan, K.; Hayes, S.; Vath, C. Incidence of falls, risk factors for falls, and fall-related fractures in individuals with diabetes and a prior foot ulcer. Diabetes care, 2002, 25(11), 1983-1986.

8. Centers for Disease Control and Prevention (CDCP). History of foot ulcer among persons with diabetes---Unites States, 2000-2002. Morbidity \& Mortality Weekly Report. 2003; 52: 10981102.

9. Seki, M.; Tanaka, T.; Nawa, H.; Usui, T.; Fukuchi, T.; Ikeda, K.; Abe, H.; Takei, N. Involvement of brain-derived neurotrophic factor in early retinal neuropathy of streptozotocininduced diabetes in rats: therapeutic potential of brain-derived neurotrophic factor for dopaminergic amacrine cells. Diabetes. 2004, 53(9), 2412-2419.

10. Moran, A.; Palmas, W.; Field, L.; Bhattarai, J.; Schwartz, J.E.; Weinstock, R.S.; Shea, S. Cardiovascular autonomic neuropathy is associated with microalbuminuria in older patients with type 2 diabetes. Diabetes care. 2004, 27(4), 972-977.

11. Svensson, M.; Eriksson, J.W.; Dahlquist, G. Early glycemic control, age at onset, and development of microvascular complications in childhood-onset type 1 diabetes: a populationbased study in northern Sweden. Diabetes care 2004, 27(4), 955-962.

12. Saely, C.H.; Aczel, S.; Marte, T.; Langer, P.; Drexel, H. Cardiovascular complications in Type 2 diabetes mellitus depend on the coronary angiographic state rather than on the diabetic state. Diabetologia 2004, 47(1), 145-146.

13. Bearse, M.A.; Han, Y.; Schneck, M.E.; Barez, S.; Jacobsen, C.; Adams, A.J. Local multifocal oscillatory potential abnormalities in diabetes and early diabetic retinopathy. Invest Ophthal Vis Sci. 2004, 45(9), 3259-3265.

14. Hove, M.N.; Kristensen, J.K.; Lauritzen, T.; Bek, T. The prevalence of retinopathy in an unselected population of type 2 diabetes patients from Århus County, Denmark. Acta Ophthalmol Scand. 2004, 82(4), 443-448.

15. Huang, C.; Kim, Y.; Caramori, M.L.A.; Fish, A.J.; Rich, S.S.; Miller, M.E.; Russell, G.B.; Mauer, M. Cellular basis of diabetic nephropathy: II. The transforming growth factor- $\beta$ system and diabetic nephropathy lesions in type 1 diabetes. Diabetes. 2002, 51(12), 3577-3581. 
16. Shukla, N.; Angelini, G.D.; Jeremy, J.Y.- to: Looker HC, Fagot-Campagna A, Gunter EW et al. (2003) Homocysteine as a risk factor for nephropathy and retinopathy in Type 2 diabetes. Diabetologia. 2004, 46, 766-772.

17. Ahmed, A.M. History of diabetes mellitus, Saudi Med J. 2002, 23, 373-378.

18. Diabetes mellitus history-from ancient to modern times.

19. Sicree R, Shaw J and Zimmet P, 2006. The Global Burden. Diabetes and Impaired Glucose Tolerance, Prevalence and Projections. In: Gan D. ed. Diabetes Atlas, 2rd edn. Brussels: International Diabetes Federation pp.16-103.

20. Piero, M.N.; Nzaro, G.M.; Njagi, J.M. Diabetes mellitus-a devastating metabolic disorder. Asian J Biomed Pharmaceut Sc. 2015, 5(40), 1.

21. World Health Organization,1994, Prevention of diabetes mellitus,technical Report series np.844,Geneva:world health organization.

22. Arora, S.; Ojha, S.K.; Vohora, D. Characterisation of streptozotocin induced diabetes mellitus in swiss albino mice. Glo J of Pharmacol. 2009, 3(2), 81-84.

23. Dwivedi,Girish\&Dwivedi,Shridhar,History of Medicine:Sushruta-the Clincian-Teacher par Excellence;National Informatics Centre ;2007(Government of India)

24. The Expert Committee on the Diagnosis and Classification of Diabetes Mellitus. Report of the Expert Committee on the Diagnosis and Classification of Diabetes Mellitus. Diabetes Care 1997;20:0183-97.

25. Bastaki, S.; Review Diabetes mellitus and its treatment, Int J Diabetes \& Metabolism. 2005, 13, 111-134.

26. Mane, P.B.; Antre, R.V.; Oswal, R.J. Antidiabetic drugs: An overview. Int. J. Pharm. Chem. Sci. 2012, 1(1), 301-306.

27. Harikumar, K.; Hemalatha, G.J.; Kumar, B.; Lado, S.F.S. A review on diabetes mellitus. Int J Novel Trends Pharm Sci. 2014,4(6), 201-217.

28. Seki, M.; Tanaka, T.; Nawa, H.; Usui, T.; Fukuchi, T.; Ikeda, K.; Abe, H.; Takei, N. Involvement of brain-derived neurotrophic factor in early retinal neuropathy of streptozotocininduced diabetes in rats: therapeutic potential of brain-derived neurotrophic factor for dopaminergic amacrine cells. Diabetes. 2004, 53(9), 2412-2419. 
29. Wallace, C.; Reiber, G.E.; LeMaster, J.; Smith, D.G.; Sullivan, K.; Hayes, S.; Vath, C. Incidence of falls, risk factors for falls, and fall-related fractures in individuals with diabetes and a prior foot ulcer. Diabetes care 2002, 25(11), 1983-1986.

30. American Diabetes Association. Standards of medical care in diabetes. Diabetes Care, 2009, 32(suppl 1), s15.

31. Centers for Disease Control and Prevention (CDCP). History of foot ulcer among persons with diabetes- Unites States, 20002002. Morbidity \& Mortality Weekly Report. 2003; 52: 10981102.

32. American Diabetes Association. Standards of medical care in diabetes. Diabetes Care, 2009, 32(suppl 1), s13-14.

33. Fajans, S.S.; Bell, G.I.; Polonsky, K.S. Molecular mechanisms and clinical pathophysiology of maturity-onset diabetes of the young. N Engl J Med. 2001, 345, 971-980.

34. Zimmet, P.Z.; Tuomi, T.; Mackay, R.; Rowley, M.J.; Knowles, W.; Cohen, M, Lang, D.A. Latent autoimmune diabetes mellitus in adults (LADA): The role of antibodies to glutamic acid decarboxylase in diagnosis and prediction of insulin dependency. Diabetic Med, 1994, 11, 299303.

35. Zimmet, P.Z. The pathogenesis and prevention of diabetes in adults. Diabetes care, 1995, 18, 1050-6.

36. Hother-Nielsen, O.; Faber, O.; Sørensen, N.S.; Beck-Nielsen, H. Classification of newly diagnosed diabetic patients as insulin requiring or non-insulin requiring based on clinical and biochemical variables. Diabetes care, 1988, 11, 531-537.

37. Defronzo, R.A.; Bonadonna, R.C.; Ferrannini, E, et al. Pathogenesis of NIDDM. International textbook of diabetes mellitus. 2nd Edn. Chichester: john wiley, 1997, 635-712.

38. Mooy, J.M.; Grootenhuis, P.A.; de Vries, H.; Valkenburg, H.A.; Bouter, L.M.; Kostense, P.J.; Heine, R.J. Prevalence and determinants of glucose intolerance in a dutch population. The hoorn study. Diabetes care. 1995, 18, 1270-73.

39. Harris, M.I. Undiagnosed NIDDM: clinical and public health issues. Diabetes care. 1993, 16(4), 642-652.

40. Campbell, P.J.; Carlson, M.G. Impact of obesity on insulin action in NIDDM. Diabetes 1993, 42(3), 405-410.

41. Raju SM, Raju B (2010). Illustrated medical biochemistry. 2nd Edition. 
42. Holt, G.I. Diagnosis, epidemiology and pathogenesis of diabetes mellitus an update for Psychiatrists. Brit J Psychiat. 2004, 184, s55- s63.

43. Froguel, P.; Zouali, H.; Vionnet, N.; Velho, G.; Vaxillaire, M.; Sun, F.; Lesage, S.; Stoffel, M.; Takeda, J.; Passa, P.; Permutt, M.A.; Beckmann, J.S.; Bell, G.I.; Cohen, D. Familial hyperglycemia due to mutations in glucokinase definition of a subtype of diabetes mellitus. $\mathrm{N}$ Engl J Med. 1993, 328(10), 697-702.

44. Ozougwu, J.; Obimba, K.; Belonwu, C.D.; Unakalamba, C.D. The pathogenesis and pathophysiology of type 1 and type 2 diabetes mellitus; J Physiol Pathophysiol. 2013, 4(4), 4657.

45. Maity, P.; Hansda, D.; Bandyopadhyay, U.; Mishra, D.K. Biological activities of crude extracts and chemical constituents of Bael, Aegle marmelos (L.) Corr. Indian J Exp Biol. 2009, 47, 849861.

46. Rawat, M.; Parmar, N. Medicinal Plants with Antidiabetic Potential- A review; AmericanEurasian J Agric \& Environ Sci. 2013, 13(1), 81-94.

47. Ahmad Ghorbani,Best herbs for managing diabetes: A review of clinical studies,Brazilian Journal of Pharmaceutical Sciences, 49, 3, jul./sep., 2013.

48. Shanmugasundaram,ERB; Rajeswari, G .; Baskaran , K .; Kmar, BRR ; Shanmugasundaram, KR.; Ahmath, BK. Use of Gymnema sylvestre leaf extract in the control of blood glucose in insulin-dependent diabetes mellitus. J. Ethnopharmacol., v.30, p.281-294, 1990.

49. Jofee, D.J.; Freed, S.H. Effect of extended release Gymnema sylvestre leaf extract alone or in combination with oral hypoglycemics or insulin regimens for type 1 and type 2 diabetes. Diabetes Control Newsletter, v.76, p.30. 2001.

50. Iimail, M.Y.M. Clinical evaluation of antidiabetic activity of Trigonella seeds and Aegle marmelos leaves. World Appl. Sci. J., 7, 1231-1234, 2009a.

51. Waheed, A.; Miana, G.A.; Sharafatullah, T.; Ahmad, S.I. Clinical investigation of hypoglycemic effect of unripe fruit on Momordica charantia in type-2 (NIDDM) diabetes mellitus. Pakistan J. Pharmacol., v.25, p.7-12, 2008.

52. Tran N, Pham B, Le L. Bioactive Compounds in Anti-Diabetic Plants: From Herbal Medicine to Modern Drug Discovery. Biology (Basel). 2020 Aug 28;9(9):252.

53. Vuksan, V.; Sievenpiper, J.L.; Koo, V.Y.Y.; Francis, T.; Beljan-zdravkovic, U.; Xu, Z.; Vidgen, E. American ginseng (Panax quinquefolius L) reduces postprandial glycemia in 
nondiabetic subjects and subjects with type 2 diabetes mellitus. Arch. Intern. Med., v.160, p.1009-1013, 2000a.

54. Vuksan, V.; Stavro, M.P.; Sievenpiper, J.L.; Beljan-zdravkovic, U.; Leiter, L.A.; Josse, R.G.; Xu, Z. Similar postprandial glycemic reductions with escalation of dose and administration time of American ginseng in type 2 diabetes mellitus. Diabetes Care, v.23, p.1221-1226, $2000 \mathrm{~b}$.

55. Dixit, N.; Baboota, S.; Kohli, K.; Ahmad, S.; Ali, J. Silymarin: a review of pharmacological aspects and bioavailability enhancement approaches. Indian J. Pharmacol., v.39, p.172$179,2007$.

56. Fallah Hoseini, H.; Larijani, B.; Heshmat, R.; Fakhrzadeh, H.; Radjabipour, B.; Toliat, T.; Raza, M. The efficacy of Silybum marianum (L.) gaertn. (Silymarin) in the treatment of type II diabetes: a randomized, double-blind, placebo-controlled, clinical trial. Phytother. Res., v.20, p.1036-1039, 2006.

57. Kajimoto, O.; Kawamori, S.; Shimoda, H.; Kawahara, Y.; Hirata, H.; Takahashi, T. Effects of a diet containing Salacia reticulata on mild type 2 diabetes in humans. A placebocontrolled, cross-over trial. J. Jpn. Soc. Nutr. Food Sci., v.53, p.199-205, 2000.

58. Jayawardena, M.H.S.; Alwis, N.M.W.; Hettigoda, V.; Fernando, D.J.S. A double blind randomised placebo controlled cross over study of a herbal preparation containing Salaciareticulata in the treatment of type 2 diabetes. J. Ethnopharmacol., v.97, p.215-218, 2005.

59. Ghorbani, A.; Rakhshandeh, H. The most effective herbs for diabetes. Mashhad: Mashhad University of Medical Sciences Publisher, p.21-127, 2012.

60. Kassaian, N.; Azadbakht, L.; Forghani, B.; Amini, M. Effect of fenugreek seeds on blood glucose and lipid profiles in type 2 diabetic patients. Int. J. Vitam. Nutr. Res., v.79, p.3439, 2009.

61. Eldin, I.M.T.; Ahmed, E.M.; Abd elwahab, H.M. Preliminary study of the clinical hypoglycemic effects of Allium cepa (red onion) in type 1 and type 2 diabetic patients. Env. Health Insights, v.4, p.71-77, 2010.

62. Reza Ghahramani M.Sc., Maryam Eidi Ph.D., Hossein Ahmadian M.Sc.Mostafa Hamidi Nomani M.Sc., Roya Abbasi B.Sc. Marzieh Alipour M.Sc., Ali Anissian Ph.D.,Anti- 
diabetic Effect of Portulaca oleracea (Purslane) Seeds in Alloxan-induced Diabetic Rats,International Journal of Medical Laboratory 2016;3(4):282-289.

63. Wadood, A.; Wadood, N.; Shah, S.A. Effects of Acacia Arabica and Caralluma edulis on blood glucose levels of normal and alloxan, rabbits. J Pak Med Assoc. 1989, 39(8), 208-12.

64. Liu, I.M.; Liou, S.S.; Lan, T.W.; Hsu, F.L.; Cheng, J.T. Myricetin as the active principle of Abelmoschus moschatus to lower plasma glucose in streptozotocin-induced diabetic rats. Planta medica. 2005, 71(07), 617-621.

65. Liu, I.M.; Tzeng, T.F.; Liou, S.S.; Lan, T.W. Improvement of insulin sensitivity in obese Zucker rats by myricetin extracted from Abelmoschus moschatus. Planta Medica. 2007, 73(10), 10541060.

66. Ajabnoor, M.A. Effect of aloes on blood glucose levels innormal and alloxan diabete mice, $\mathrm{J}$ Ethnopharmacol. 1990, 28, 215-20.

67. Abou El Hamd, H.M.; El-Sayed, M.A.; Hegazy, M.E.; Helaly, S.E.; Esmail, A.M.; Mohamed, N. S. Chemical constituents and biological activities of Artemisia herba-alba. Rec Nat Prod. 2010, 4(1), 1-25.

68. Nimenibo-Uadia, R. Effect of aqueous extract of Canavalia ensiformis on hyperlipidaemia and hyperketonaemia in alloxan- induced diabetic rats; Biokemistri. 2003, 15(1), 7-15.

69. Shen, S.C.; Cheng, F.C; Wu, N.J. Effect of guava (Psidium guajava Linn.) leaf soluble solids on glucose metabolism in type 2 diabetic rats. Phytother Res. 2008, 22(11), 1458-64.

70. Sharma, S.; Tandon, S.; Semwal, B.C.; Singh, K. Momordica charantia Linn: A comprehensive Revie on Bitter Remedy; J Pharm Res. 2011, 1, $42-47$.

71. Uebanso, T.; Arai, H.; Taketani, Y.; Fukaya, M.; Yamamoto, H.; Mizuno, A.; Uryu, K.; Hada, T.; Takeda, E. Extracts of Momordica charantia suppress postprandial hyperglycemia in rats. J Nutr Sci Vitaminol. 2007, 53(6), 482-488.

72. Maity, P.; Hansda, D.; Bandyopadhyay, U.; Mishra, D.K. Biological activities of crude extracts and chemical constituents of Bael, Aegle marmelos (L.) Corr. Indian J Exp Biol. 2009, 47, 849861.

73. Rawat, M.; Parmar, N. Medicinal Plants with Antidiabetic Potential- A review; AmericanEurasian J Agric \& Environ Sci. 2013, 13(1), 81-94. 
74. Lo, H.Y.; Li, T.C.; Yang, T.Y.; Li, C.C.; Chiang, J.H.; Hsiang, C.Y.; Ho, T.Y. Hypoglycemic effects of Trichosanthes kirilowii and its protein constituent in diabetic mice: the involvement of insulin receptor pathway. BMC Complement Altern Med. 2017, 17(1), 53.

75. Zhou, Y.X.; Xin, H.L.; Rahman, K.; Wang, S.J.; Peng, C.; Zhang, H. Portulaca oleracea L.: a review of phytochemistry and pharmacological effects. BioMed Res Internat. 2015.

76. Ramadan, B.K.; Schaalan, M.F.; Tolba, A.M. Hypoglycemic and pancreatic protective effects of Portulaca oleracea extract in alloxan induced diabetic rats. BMC Complement Altern Med. 2017, 17(1), 37.

77. Victor, M.; Abbey, P.A.; Joseph, Y.; Jonathan, Z.; Bobai, Y.K.; Maria, O. An Underexploited Tropical Plant with Promising Economic Value and the Window of Opportunities for Researchers: Cnidoscolus aconitifolius. Am J Food Sci Nutr Res. 2016, 3(6), 177.

78. Achi, N.K.; Ohaeri, O.C.; Ijeh, I.I.; Eleazu, C. Modulation of the lipid profile and insulin levels of streptozotocin induced diabetic rats by ethanol extract of Cnidoscolus aconitifolius leaves and some fractions: Effect on the oral glucose tolerance of normoglycemic rats. Biomed Pharmacother. 2017, 86, 562-569.

79. Akter, F.; Rahman, M.M.; Mostofa, M.; Chowdhury, E.H. Anti-diabetic effect of neem and spirulina in alloxan induced diabetic mice. Int. J Curr Res Acad Rev. 2014, 2(4), 124-134.

80. 61 Subramoniam, A.; Pushpangadan, P.; Rajasekharan, S.; Evans, D.A.; Latha, P.G.; Valsaraj, R. Effects of Artemisia pallens Wall., on blood glucose levels in normal ad alloxan-induced diabetic rats. J Ethnopharmacol 1996, 50(1), 13-7.

81. Sahane, R.S.; Wankhade, V.M.; Nandi, P. Effect of Areca catechu L. leaf extract on type II diabetes in rats. Int J Pharm Res Bio-Sci. 2013, 4(10), 731-37.

82. Chempakam, B.; Hypoglycemic activity of arecoline in betel nut Areca catechu L. Indian J Exp Biol. 1993, 31(5): 474-/75.

83. Kanagavalli, U.; Bhuvaneshwari, B.; Sadiq, M.A. Anti-diabetic activity of Boerhaavia diffusa against alloxan-induced diabetic rats. Int J Pharma Bio Sci. 2015, 6(5), 1215-1219.

84. Rao, K.N.; Krishna, M.B.; Srinivas, N. Effect of aqueos extract of leaves of Boerhaavia diffusa; Trop J Pharm Res. 2004, 3, 305.

85. Bharati, A.C.; Sahu, A.N. Ethnobotany, phytochemistry and pharmacology of Biophytum sensitivum DC. Pharmacogn Rev. 2012, 6(11), 68. 
86. de Sousa Lino, C.; Diógenes, J.P.L.; Pereira, B.A.; Faria, R.A.P.G.; Neto, M.A.; Alves, R.S.; de QUEIROZ, M.G.R.; de SOUSA, F.C.F.; Viana, G.S.B. Antidiabetic activity of Bauhinia fortica extracts in alloxan -diabetic rats. Biol Pharm Bull. 2004, 27, 125-27.

87. Fuentes, O.; Arancibia-Avila, P.; Alarcón, J. Hypoglycemic activity of Bauhinia candicans in diabetic induced rabbits. Fitoterapia. 2004, 75(6), 527-532.

88. Chang, S.L.; Chang, C.L.T.; Chiang, Y.M.; Hsieh, R.H.; Tzeng, C.R.; Wu, T.K.; Sytwu, H.K.; Shyur, L.F.; Yang, W.C. Polyacetylenic compounds and butanol fraction from Bidens pilosa can modulate the differentiation of helper $\mathrm{T}$ cells and prevent autoimmune diabetes in nonobese diabetic mice. Planta Medica. 2004, 70(11), 1045-1051.

89. Shibly, A.Z.; Zohora, F.T.; Islam, M.S.; Islam, M.R. A comprehensive review on ethno pharmacological antidiabetic potential of traditional ayurvedic plants of Bangladesh; J Pharmacogn Phytochem. 2015, 4(1), 107-112.

90. Singh, R.; Rajasree, P.H.; Sankar, C. Screening for anti-diabetic activity of the ethanolic extract of Bryonia alba roots. Int J Pharm Biol Sci. 2012, 2(3), 210-5.

91. Sokeng, S.D.; Rokeya, B.; Mostafa, M.; Nahar, N.; Mosihuzzaman, M.; Ali, L.; Kamtchouing, P. Antihyperglycemic effect of bridelia ndellensis ethanol extract and fractions in streptozotocin-induced diabetic rats; Afr J Tradit Complement Altern Med. 2005, 2, 94-102.

92. Jawla, S.; Kumar, Y.; Khan, M.S.Y. Hypoglycemic activity of Bougainvillea spectabilis stem bark in normal and alloxan-induced diabetic rats. Asian Pac J Trop Biomed. 2012, 2(2), S919-S923.

93. Khan, A.K.; Akhtar, S.; Mahtab, H. Treatment of diabetes mellitus with Coccinia indica. Brit Med J. 1980, 280(6220), 1044.

94. Rasineni, K.; Bellamkonda, R.; Singareddy, S.R.; Desireddy, S. Antihyperglycemic activity of Catharanthus roseus leaf powder in streptozotocin-induced diabetic rats. Pharmacognosy Res. 2010, 2(3), 195-201.

95. Babu, V.; Gangadevi, T.; Subramoniam, A. Antidiabetic activity of ethanol extract of Cassia kleinii leaf in streptozotocin-induced diabetic rats and isolation of an active fraction and toxicity evaluation of the extract. Indian J Pharmacol. 2003, 35(5), 290-296.

96. Kumar, G.P.S.; Arulselvan, P.; Kumar, D.S.; Subramanian, S.P. Anti-diabetic activity of fruits of Terminalia chebula on streptozotocin induced diabetic rats. J Health Sci. 2006, 52(3), 283291. 
97. Attele, A.S.; Zhou, Y.P.; Xie, J.T.; Wu, J.A.; Zhang, L.; Dey, L.; Pugh, W.; Rue, P.A.; Polonsky, K.S.; Yuan, C.S. Antidiabetic effects of Panax ginseng berry extract and the identification of an effective component. Diabetes. 2002, 51(6), 1851-1858.

98. Soni, Y.; Mochi, R.; Gahlot, G. Effect of aloe vera juice on diabetic and diabetic retinopathy subjects. Indian J Life Sci. 2014, 4(1), 41.

99. Kaleem, M.; Asif, M.; Ahmed, Q.U.; Bano, B. Antidiabetic and antioxidant activity of Annona squamos extract in streptozotocin induced diabetic rats. Singapore Med J. 2006, 47(8), 670-5.

100. Agyemang, K.; Han, L.; Liu, E.; Zhang, Y.; Wang, T.; Gao, X. Recent advances in Astragalus membranaceus anti-diabetic research: pharmacological effects of its phytochemical constituents. Evid Based Complement Alternat Med. 2013, Article ID 654643.

101. Nazeerullah, K.; Sunil, K.; Pal, S.R.; Neelam, D. A pharmacognostic and pharmacological overview on Caesalpinia bonducella. Res J Pharm Bio Chem Sci. 2012, 3(1), 440-496.

102. Zia-Ul-Haq, M.; Ćavar, S.; Qayum, M.; Imran, I.; Feo, V.D. Compositional studies: antioxidant and antidiabetic activities of Capparis decidua (Forsk.) Edgew. Int J Mol Sci. 2011, 12(12), 8846-8861.

103. Badole, S.; Patel, N.; Bodhankar, S.; Jain, B.; Bhardwaj, S. Antihyperglycemic activity of aqueous extract of leaves of Cocculus hirsutus (L.) Diels in alloxan-induced diabetic mice. Indian J Pharmacol. 2006, 38(1), 49.

104. Ogbunugafor, H.A.; Ilodigwe, E.E.; Ajaghaku, D.L.; Ezekwesili, C.N.; Okafor, C.S.; Ajuzieogu, C.F.; Madunatum, S.U. Dioscorea dumetorum-fed rats exhibited decreased body weight, blood glucose, and insulin in stz-induced diabetes. Funct food health dis. 2014, 4(2), 87-97.

105. Arai, I.; Amagaya, S.; Komatsu, Y.; Okada, M.; Hayashi, T.; Kasai, M.; Arisawa, M.; Momose, Y. Improving effects of the extracts from Eugenia uniflora on hyperglycemia and hypertriglyceridemia in mice. J Ethnopharmacol. 1999, 68(1-3), 307-314.

106. Daisy, P.; Rayan, N.A.; Rajathi, D. Hypoglycemic and Other Related Effects of Elephantopus scaber. J Bio Sci. 2007, 7(2), 433-437.

107. Singh, R.K.; Mehta, S.; Jaiswal, D.; Rai, P.K.; Watal, G. Antidiabetic effect of Ficus bengalensis aerial roots in experimental animals. J Ethnopharmacol. 2009, 123(1), 110-4.

108. Adaramoye, O.A. Antidiabetic effect of kolaviron, a biflavonoid complex isolated from Garcinia kola seeds, in Wistar rats. Afr. Health Sci. 2012, 12(4), 498-506. 
109. Yokozawa, T.; Kim, H.Y.; Yamabe, N. Amelioration of diabetic nephropathy by dried Rehmanniae Radix (Di Huang) extract. Am J Chin Med. 2004, 32(06), 829-839.

110. Yan, Y.M.; Fang, P.; Yang, M.T.; Li, N.; Lu, Q.; Cheng, Y.X. Anti-diabetic nephropathy compounds from Cinnamomum cassia. J Ethnopharm. 2015, 165, 141-147.

111. Mishra, A.; Srivastava, R.; Srivastava, S.P.; Gautam, S.; Tamrakar, A.K.; Maurya, R.; Srivastava, A.K. Antidiabetic activity of heart wood of Pterocarpus marsupium Roxb. and analysis of phytoconstituents. Indian J Exp Bio. 2013, 51, 363-374.

112. Mowl, A.; Alauddin, M.; Rahman, M.; Ahmed, K. Antihyperglycemic effect of Trigonella foenum-graecum (Fenugreek) seed extract in alloxan-induced diabetic rats and its use in diabetes mellitus: a brief qualitative phytochemical and acute toxicity test on the extract. Afr J Tradit Complement Altern Med. 2009, 6(3), 255-261.

113. Ohno, H.; Nagai, J.; Kurokawa, T.; Sonoda, M.; Yumoto, R.; Takano, M. Effect of Aqueous Extract from The Root Cortex of Aralia elata on Intestinal alpha-Glucosidases and Postprandial Glycemic Response in Mice. Int J Phytomedicine. 2012, 4(4), 567.

114. Sharma, P.; Dubey, G.; Kaushik, S. Chemical and medico-biological profile of Cyamopsis tetragonoloba (L) Taub: an overview. J Appl Pharm Sci. 2011, 1(02), 32-37.

115. Jiang, S.; Du, P.; An, L.; Yuan, G.; Sun, Z. Anti-diabetic effect of Coptis Chinesis polysaccharide in high fat diet with STZ-induced diabetic mice. Int J Biol Macromol. 2013, 55, 118-22.

116. 99. Helal, E.G.; Abd-Elwahab, S.M.; Atia, T.A.; Mohammad, A.A. Hypoglycemic Effect of the Aqueous Extracts of Lupinus albus, Medicago sativa (seeds) And their Mixture on Diabetic Rats; $\quad$ Egypt J Hosp Med. 2013, 52, 685-698.

117. Choubey, A.; Ojha, M.; Mishra, A.; Mishra, S.; Patil, U.K. Hypoglycemic and antihyperglycemic effect of ethanolic extract of whole plant of Lawsonia inermis (henna) in streptozotocin induced diabetic rats. Int J Pharm Sci Res. 2010, 1, 74-77.

118. Nadig, P.D.; Revankar, R.R.; Dethe, S.M.; Narayanswamy, S.B.; Aliyar, M.A. Effect of Tinospora cordifolia on experimental diabetic neuropathy; Indian J Pharmacol. 2012, 44(5), 580-583.

119. Shidfar, F.; Rajab, A.; Rahideh, T.; Khandouzi, N.; Hosseini, S.; Shidfar, S. The effect of ginger on gycemic markers in patients with type- 2 diabetes; J Complement Integr Med. 2015, (2), 165-70. 
120. Singh, P.; Khosa, R.L.; Mishra, G.; Jha, K.K. Antidiabetic activity of ethanolic extract of cyperus rotundus rhizomes in strptozotocin induced diabetic mice; J Pharm Bioallied Sci. 2015, 7(4), 289-292.

121. Ashraf, M.U.; Muhammad, G.; Hussain, M.A.; Bukhari, S.N. Cydonia oblonga M., A Medicinal Plant Rich in Phytonutrients for Pharmaceuticals; Front Pharmacol. 2016, 7, 163.

122. Daisy, P.; Rajathi, M. Hypoglycemic Effects of Clitoria ternatea in Alloxan-induced Diabetes in Rats; Trop J Pharm Res. 2009, 8(5), 393-398.

123. Mahomed, I.M.; Ojewole, J.A.O. Hypoglycemic effect of Hypoxis hemerocallidea corm (African potato) aqueous extract in rats. Methods Find Exp Clin Pharmacol. 2003, 25(8), 61723.

124. Grat, A.M.; Flatt, P.R. Actions of the traditional anti-diabetic plant, Agrimony eupatoria (agrimony): effects on hyperglycaemia, cellular glucose metabolism and insulin secretion. Brit J Nutr. 80(1), 109-14.

125. Ezike, A.C.; Akah, P.A.; Okoli, C.C.; Okpala, C.B. Experimental evidence for the antidiabetic activity of Cajanus cajan leaves in rats. J Basic Clin Pharm. 2010, 1(2), 81.

126. Kumar, R.; Patel, D.K.; Prasad, S.K.; Sairam, K.; Hemalatha, S. Antidiabetic activity of alcoholic root extract of Caesalpinia digyna in streptozotocin-nicotinamide induced diabetic rats. Asian Pac J Trop Biomed. 2012, 2(2), S934-S940.

127. Lima, C.R.; Vasconcelos, C.F.; Costa-Silva, J.H.; Maranhão, C.A.; Costa, J.; Batista, T.M.; Carneiro, E.M.; Soares, L.A.; Ferreira, F.; Wanderley, A.G._Anti-diabetic activity of extract from Persea americana Mill. leaf via the activation of protein kinase B (PKB/Akt) in streptozotocin-induced diabetic rats. J Ethnopharmacol. 2012, 517-25. 